\title{
Pengenalan Teknologi Proses Pengecatan Untuk Meningkatkan Kompetensi Lulusan SMK
}

\author{
Nur Islahudin ${ }^{1}$, Zaenal Arifin ${ }^{2}$, Aries Jehan Tamamy ${ }^{2}$ \\ ${ }^{1,2,3}$ Fakultas Teknik, Universitas Dian Nuswantoro \\ E-mail: ${ }^{1}$ nur.islahudin@dsn.dinus.ac.id, ${ }^{2}$ xzaenal@dsn.dinus.ac.id, ${ }^{2}$ jehantammy@dsn.dinus.ac.id
}

\begin{abstract}
Abstrak
Permasalahan yang dihadapi Industri otomotif saat ini adalah gap kompetensi antara dunia industry dengan lulusan SMK. Lulusan baru SMK saat ini masih membutuhkan waktu untuk melakukan transfer skill dan knowledge serta kompetensi yang ada pada industry otomotif. Terdapat beberapa kompetensi yang ada pada industry otomotif antara lain kompetensi dalam bidang pengecoran, kompetensi dalam bidang permesinan, kompetensi dalam bidang pengecatan, kompetensi dalam bidang pengelasan dan kompetensi dalam bidang perakitan. Dari beberapa bidang kompetensi tersebut, kompetensi dalam bidang pengecatan membutuhkan waktu yang lama dalam hal transfer skill dan knowledge. Hal ini disebabkan karena proses produksi yang dijalankan pada bagian pengecatan masih menggunakan teknologi manual sehingga membutuhkan kompetensi yang cukup untuk operator produksinya. Agar waktu transfer knowledge operator produksi dalam bidang pengecatan tidak terlalu lama diperlukan kerjasama antara industry dengan pihak sekolah untuk dapat menyiapkan lulusan SMK yang mempunyaim kompetensivdalam bidang pengecatan. Dari kondisi di atas penulis mencoba menawarkan solusi kepada pihak sekolah untuk mengurangi gap kompetensi antara industry dan lulusan smk dengan memberikan pelatihan tentang teknologi pengecatan yang berisi teori dan praktek tentang pengecatan. Dari hasil yang telah dilakukan siswa tampak antusias dan semangat dalam mengikuti pelatihan yang telah di rancang serta dapat meningkatkan pemahaman tentang teknologi pengecatan di industry otomotif.
\end{abstract}

Kata kunci: pengecatan, spraygun, atomisasi

\section{Abstract}

The problem facing the automotive industry today is the competency gap between the industrial world and vocational graduates. Today's new SMK graduates still need time to transfer skills and knowledge and competencies that exist in the automotive industry. There are several competencies that exist in the automotive industry, among others, competency in the field of casting, competence in the field of machinery, competence in the field of painting, competence in the field of welding and competence in the field of assembly. From these competency fields, competency in painting requires a long time in terms of skill and knowledge transfer. This is because the production process carried out in the painting section still uses manual technology so that it requires sufficient competence for the production operator. So that the time of transfer of knowledge of production operators in the field of painting is not too long it takes collaboration between industry and the school to be able to prepare vocational graduates who have competence in the field of painting. From the above conditions the writer tries to offer a solution to the school to reduce the competency gap between industry and high school graduates by providing training on painting technology that contains theory and practice about painting. From the results that have been done, students look enthusiastic and enthusiastic in participating in the training that has been designed and can improve understanding of the painting technology in the automotive industry.

Keyword : painting plastic, spraygun, atomization 


\section{PENDAHULUAN}

Dunia industry saat ini telah mengalami perubahan yang cukup signifikan dalam hal proses manufaktur. Teknologi otomasi mendominasi perkembangan untuk proses produksi di industry manufaktur. Salah satu industry manufaktur yang juga melakukan perubahan-perubahan dalam system produksi nya adalah industry otomotif. Dari data AISI dan Gaikindo menunjukan bahwa terjadi peningkatan pertumbuhan pada industry otomotif di Indonesia yang dapat menjadikan Indonesia sebagai prospektif market bagi para pelaku industri manufaktur. Selain itu data kementerian perindustrian republik Indonesia menunjukan bahwa rasio kepemilikan sepedamotor di Indonesia masih terbilang rendah dibandingkan negara-negara lain. Sebagai contoh pada tahun 2013 rasio kepemilikan sepedamotor masyarakt indonesi adalah 1:3 yang artinya satu unit kendaraan bermotor digunakan untuk tiga orang [1]. Rasio kepemilikan ini masih mungkin untuk dikembangkan ke depannya.

Dari perkembangan pasar industry otomotif yang masih akan terus tumbuh, permintaan akan karyawan untuk operator produksi juga akan mengikuti perkembangan tersebut. Salah satu stakeholder dari industry manufaktur dalam hal penyediaan karyawan untuk operator produksi adalah Sekolah Menengah Kejuruan (SMK). Lulusan SMK diharapkan dapat memenuhi kebutuhan operator produksi untuk industry manufaktur dari segi kompetensi karena program SMK dibekali dengan beberapa kompetensi dasar di industri manufaktur. Namun terdapat beberapa kompetensi yang masih belum bisa diberikan secara sepenuhnya di bangku sekolah karena beberapa kendala terkait proses produksi. Berikut ini gambaran proses produksi di industry otomotif khusunya untuk pembuatan sepedamotor.

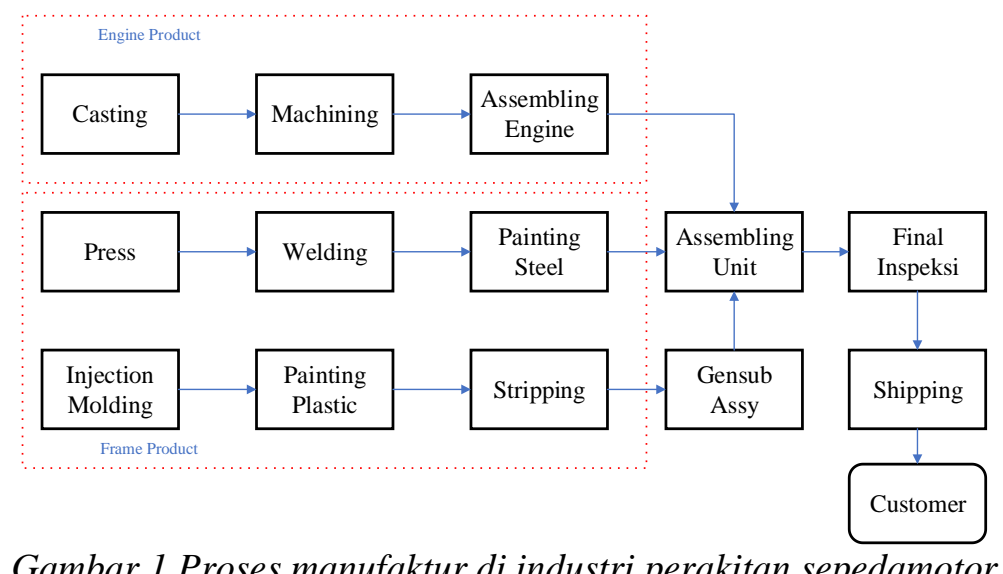

Salah satu bagian dari industri perakitan sepedamotor yang membutuhkan kompetensi yang cukup tinggi karena mengandalkan skill dari kompetensi operator produksi adalah bagian pengecatan. Proses ini masih menjadi proses yang cukup sulit karena proses produksi yang dijalankan masih menggunakan proses manual. Beberapa perubahan telah dikembangkan untuk meningkatkan performance dari proses pengecatan, namun masih terdapat beberapa kendala yang dihadapi oleh bagian pengecatan. Selain itu transfer knowledge yang dibutuhkan oleh bagian pengecatan ketika terjadi pergantian operator juga membutuhkan waktu belajar yang lama agar dapat menguasai skill dari proses pengecatan sehingga ketika ada pergantain karyawan baru untuk mempelajari proses pengecatan akan akan berdampak terhadap kualitas dari proses pengecatan tersebut. Oleh karena itu diperlukan suatu system manajemen pengetahuan untuk dapat menjembatani lama nya proses untuk mempelajari proses pengecatan. Salah satu metode yang dapat diambil untuk mengurangi gap kompetensi karyawan baru dan karyawan lama dapat dilakukan dengan memberikan masukan terhadap calon karyawan baru. Namun beberapa kendala akan dihadapi apabila proses manajemen pengetahuan ini dilakukan oleh industry sehingga diperlukan masukan untuk stakeholder agar dapat menyiapkan calon karyawan yang sudah dibekali oleh pengetahuan tentang proses pengecatan. 
Salah satu stakeholder yang di rasa sangat tepat untuk proses manajemen pengetahuan adalah pihak-pihak sekolah yang menghasilkan lulusan untuk kebutuhan industry. Oleh karena itu pengabdian ini ditujukan kepada sekolah-sekolah kejuruan (SMK) yang nantinya dapat menghasilkan lulusan yang mempunyai tambahan kompetensi berupa pengetahuan proses pengecatan. Lulusan di pilih karena operator yang di butuhkan untuk proses pengecatan berasal dari lulusan sekolah menengah. Pengabdian masyarakat ini di fokuskan untuk pembekalan calon lulusan SMK tentang pengetahuan proses pengecatan melalui beberapa teoritis dan praktis agar lulusan SMK dapat mengerti dan memahami tentang pengetahuan proses pengecatan. Modul proses pengecatan berisi 4 bab antara lain teknologi proses pengecatan, material cat [2],[3] kualitas pengecatan[4] dan perlalatan untuk proses pengecatan.[5]

\section{METODE PELAKSANAAN}

Pelaksanaan pengabdian ini dilakukan pada salah satu SMK di Semarang yang mempunyai jurusan tentang industry otomotif. Peserta pelatihan merupakan siswa kelas 3 SMK yang akan menghadapai persiapan untuk dunia kerja. Berikut ini rincian aktivitas pelatihan tentang kompetensi teknologi pengecatan untuk lulusan SMK.

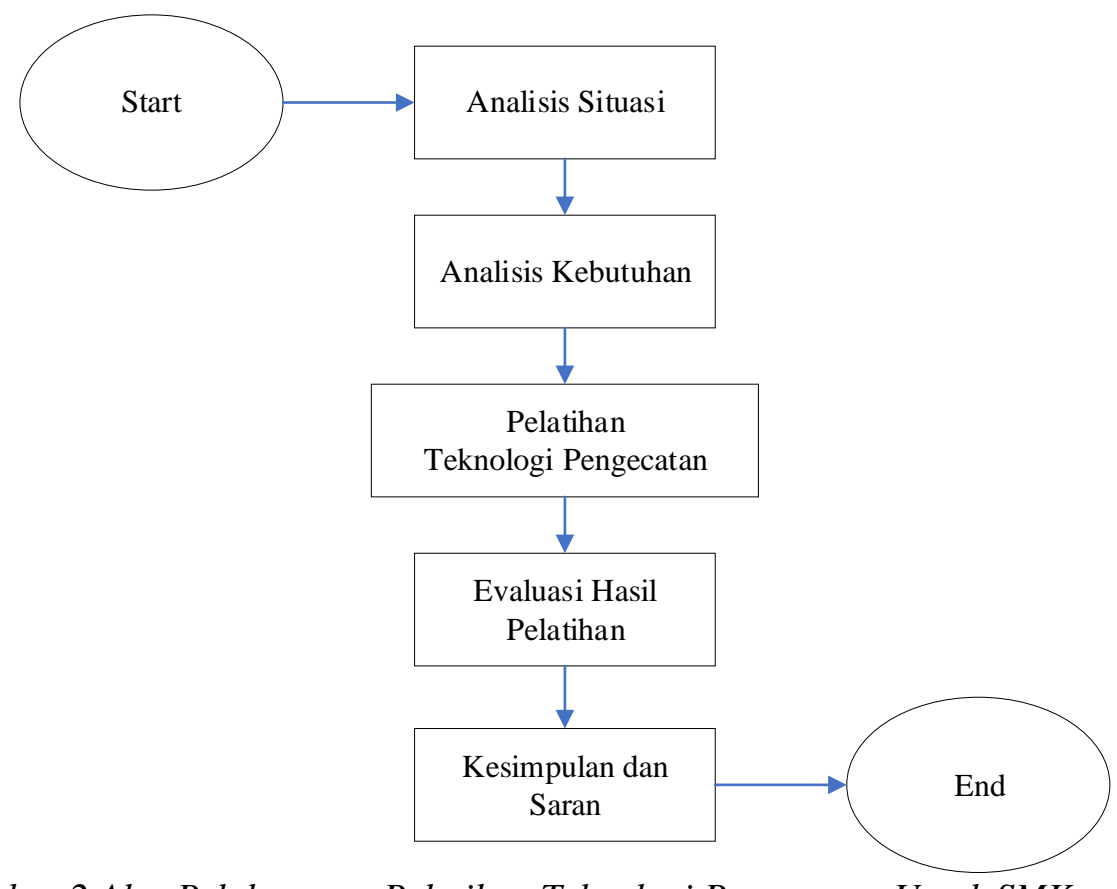

Gambar 2 Alur Pelaksanaan Pelatihan Teknologi Pengecatan Untuk SMK

\subsection{Analisis Situasi}

Pada tahapan ini dilakukan analisis untuk menemukan permasalahan yang timbul akibat gap kompetensi yang dibutuhkan oleh industry dengan kompetensi lulusan SMK saat ini. Dari identifikasi permasalahan yang telah di lakukan, gap kompetensi yang terjadi karena belum adanya penyampaian materi tentang teknologi pengecatan pada siswa-siswa SMK.

\subsection{Analisis Kebutuhan}

Pada tahap ini persiapan yang berhubungan tentang kebutuhan yang akan digunakan untuk mengatasi permasalahan yang dihadapi mitra. Beberapa kebutuhan yang harus dipersiapkan antara lain pembuatan modul pelatihan, pembelian peralatan pelatihan, koordinasi dengan mitra terkait waktu dan tempat pelaksanaan. 


\subsection{Pelatihan Teknologi Pengecatan}

Tahap ini merupakan tahap pelaksanaan pelatihan tentang teknologi proses pengecatan. Pelaksanaan pelatihan akan dilakukan pada siswa salah satu jurusan yang ada di SMK palapa semarang. Jurusan yang akan diberikan pelatihan adalah jurusan Teknik Sepeda Motor (TSM). Jurusan ini mempunyai kaitan erat dengan proses pengecatan yang ada di sepedamotor banyak dari lulusan SMK dengan jurusan TSM yang bekerja pada industry perakitan sepedamotor. Pelatihan akan dilaksanakan dengan dua sesi. Pertama penyampaian teori tentang proses pengecatan kemudian sesi kedua pelatihan praktikum tentang teori pengecatan. Pelatihan tentang proses pengecatan ini diberikan modul agar peserta pelatihan dapat memahami secara teoritis dan praktis tentang teknologi pengecatan khususnya untuk atomisasi.

\subsection{Evaluasi Hasil}

Dalam pelatihan ini terdapat dua evaluasi yang bersifat membangun dari proses pelatihan ini. Yang pertama adalah evaluasi dari segi efektifitas dari pelatihan yang dituangkan dalam bentuk pretest dan posttest tentang teknologi pengecatan. Selain evaluasi dari segi efektifitas pelatihan, durasi pelatihan juga perlu adanya perbaikan. Untuk mendapatkan lulusan SMK yang mempunyai kompetensi secara menyeluruh tentang proses pengecatan diperlukan alokasi waktu yang cukup untuk dapat memberikan efek yang cukup besar terhadap kompetensi dari lulusan SMK.

\subsection{Kesimpulan Dan Saran}

Dari pelaksanaan pengabdian masyarakat yang telah dilakukan tentang pelatihan pengetahuan teknologi proses pengecatan, para siswa SMK sangat semangat mengikuti pelatihan ini. Selain itu hasil dari pre test dan post test yang telah dilakukan mengalami peningkatan. Hal ini berarti pengetahuan siswa smk tentang teknologi proses pengecatan mengalami penengkatan. Untuk dapat meningkatkan kualitas pengabdian selanjutnya diperlukan kritik dan saran yang bersifat membangun dari segi isi materi pelatihan serta durasi pelaksanaan pelatihan agar dapat dilakukan dalam jangka waktu tertentu. Hal ini di lakukan agar lulusan SMK dapat siap terjun ke dunia industry.

\section{HASIL DAN PEMBAHASAN}

Pelaksanaan pengabdian masyarakat yang dilakukan di SMK Palapa Semarang tentang “ Pengenalan Teknologi Proses Pengecatan Untuk Meningkatkan Kompetensi SMK”, terdapat dua sesi pelatihan yang dijelaskan sebagai berikut:

\subsection{Sesi Teoritis}

Pada sesi ini para siswa dijelaskan teori tentang proses pengecatan yang telah di resume pada modul pelatihan. Sebelum teori di mulai para siswa diberikan soal pre test untuk dikerjakan. Hal ini bertujuan untuk memperoleh informasi pengetahuan siswa tentang proses pengecatan. Materi teori tentang proses pengecatan berisi 4 sub bab seperti dibawah ini :

1. Teknologi Proses Pengecatan

2. Teori Material Cat

3. Kualitas Hasil Pengecatan

4. Perlengkapan Proses Pengecatan Atomisasi

Aktifitas yang dilakukan dalam sesi teori dapat dilihat pada gambar di bawah ini : 


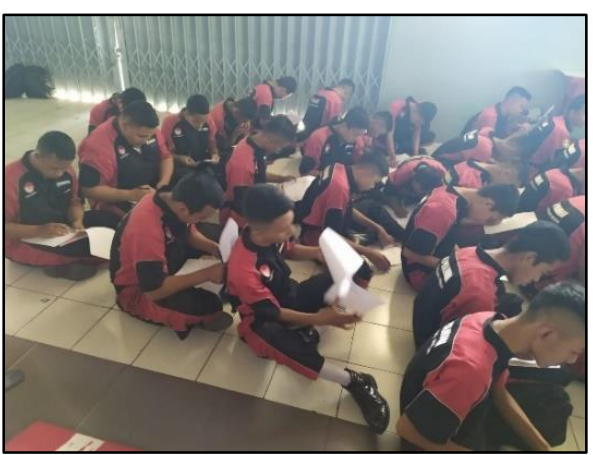

Gambar 3 Pelaksanaan pre test

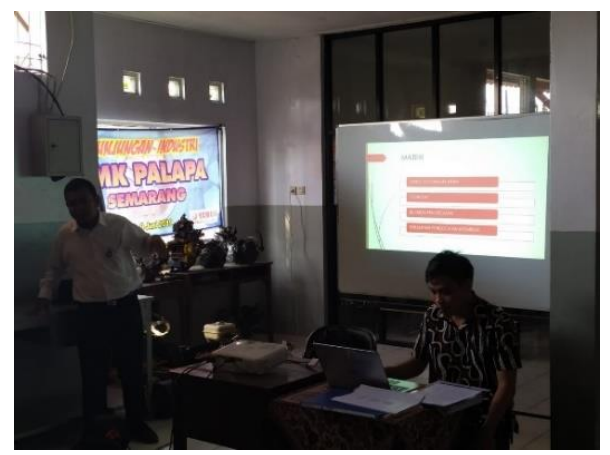

Gambar 4 Penyampaian materi teknologi proses pengecatan

\subsection{Sesi Praktik}

Pada sesi ini siswa di berikan pengetahuan tentang praktek proses pengecatan dengan penjelasan tentangpencampuran material cat dengan thinner, kemudian setting parameter yang ada pada spray gun yaitu setting pressure angin, setting delivery material cat, kemudian siswa juga di ajarkan tentang teknikteknik pengecatan yang menggunakan spray gun mulai dari jarak pengecatan, kecepatan pengecatan dan overlapping pengecatan.

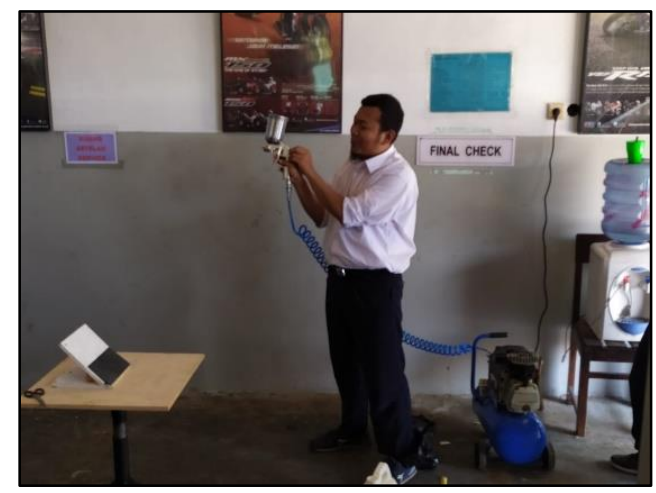

Gambar 5 Praktek setting paramter pada spray gun

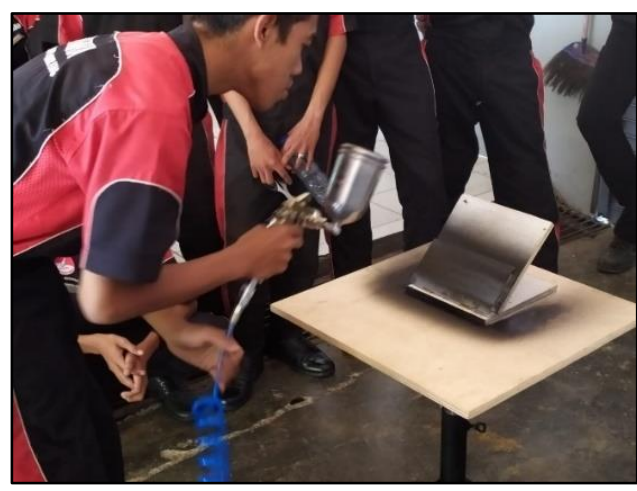

Gambar 6 Praktek proses pengecatan oleh siswa

\subsection{Analisis Pre test dan Post test}

Data yang diperoleh dari kegiatan pre test dan post test nanti nya akan diolah menggunakan metoda statistic analisis of variance (ANOVA). Metode ini digunakan untuk melihat apakah adanya perbedaan hasil dari pre test dan post test yang telah dilakukan. Berikut ini hasil pre test dan post test tentang pengenalan teknologi pengecatan di SMK palapa semarang :

Tabel 1Data hasil pre test dan post test

\begin{tabular}{|c|c|c|}
\hline \multirow{2}{*}{$\begin{array}{c}\text { No } \\
\text { Peserta }\end{array}$} & \multicolumn{2}{|c|}{ Nilai } \\
\cline { 2 - 3 } & Pre & Post \\
\hline 1 & 3 & 7 \\
\hline 2 & 3 & 5 \\
\hline 3 & 4 & 8 \\
\hline 4 & 2 & 8 \\
\hline 5 & 2 & 7 \\
\hline 6 & 3 & 2 \\
\hline
\end{tabular}

\begin{tabular}{|c|c|c|}
\hline \multirow{2}{*}{$\begin{array}{c}\text { No } \\
\text { Peserta }\end{array}$} & \multicolumn{2}{|c|}{ Nilai } \\
\cline { 2 - 3 } & Pre & Post \\
\hline 13 & 2 & 9 \\
\hline 14 & 6 & 7 \\
\hline 15 & 4 & 4 \\
\hline 16 & 2 & 6 \\
\hline 17 & 1 & 2 \\
\hline 18 & 4 & 8 \\
\hline
\end{tabular}




\begin{tabular}{|c|c|c|}
\hline \multirow{2}{*}{$\begin{array}{c}\text { No } \\
\text { Peserta }\end{array}$} & \multicolumn{2}{|c|}{ Nilai } \\
\cline { 2 - 3 } & Pre & Post \\
\hline 7 & 1 & 7 \\
\hline 8 & 3 & 7 \\
\hline 9 & 2 & 7 \\
\hline 10 & 5 & 8 \\
\hline 11 & 4 & 8 \\
\hline 12 & 5 & 9 \\
\hline
\end{tabular}

\begin{tabular}{|c|c|c|}
\hline \multirow{2}{*}{$\begin{array}{c}\text { No } \\
\text { Peserta }\end{array}$} & \multicolumn{2}{|c|}{ Nilai } \\
\cline { 2 - 3 } & Pre & Post \\
\hline 19 & 2 & 8 \\
\hline 20 & 2 & 8 \\
\hline 21 & 4 & 8 \\
\hline 22 & 3 & 8 \\
\hline 23 & 2 & 7 \\
\hline 24 & 5 & 7 \\
\hline 25 & 3 & 8 \\
\hline
\end{tabular}

Beberapa urutan pengujian anova dapat dirinci sebagai berikut [6]:

1. Membuat hipotesa

Hipotesa yang nanti akan dibuktikan adalah apakah ada perbedaan hasil kegiatan pengabdian yang telah dilakukan dengan membandingkan nilai rata-rata dan varians pre test dan post test. Hipotesa yang akan dibangun adalah sebagai berikut:

$H_{0}=$ Tidak ada perbedaan kegiatan pre test dan post test

$H_{1}=$ Ada perbedaan hasil kegiatan antara pre test dan post test

2. Menentukan kaidah pengujian

Jika : $\mathrm{F}_{\text {hitung }} \leq \mathrm{F}_{\text {tabel }}$, Maka $\mathrm{H}_{0}$ diterima

Jika : $\mathrm{F}_{\text {hitung }}>\mathrm{F}_{\text {tabel }}$, Maka $\mathrm{H}_{0}$ ditolak

3. Menghitung nilai $\mathrm{F}$ hitung dan $\mathrm{F}$ tabel

Berikut ini adalah perhitungan yang dilakukan dalam pengujian ANOVA

Tabel 2 Perhitungan dalam pengujian ANOVA

\begin{tabular}{|c|c|c|c|c|}
\hline Sumber Variasi & Jumlah Kuadrat & $\begin{array}{c}\text { Derajat } \\
\text { Bebas }\end{array}$ & Perkiraan varian & Uji F \\
\hline Antar Kelompok (between) & $\sum_{k=1}^{k} n_{k}(\bar{x} k-\overline{\mathrm{x}})^{2}$ & $\mathrm{k}-1$ & $\mathrm{MS}=\frac{S S B}{k-1}$ & \multirow{2}{*}{$\frac{\mathrm{MS}_{\mathrm{B}}}{\mathrm{MS}}$} \\
\hline Di dalam Kelompok(Within) & $\sum_{k=1}^{k} \sum_{i=1}^{n_{k}}\left(\mathrm{x}_{\mathrm{ik}}-\bar{x} k\right)^{2}$ & $\mathrm{~N}-\mathrm{k}$ & $\mathrm{MS}=\frac{S S W}{N-k}$ & \\
\hline Total & $\sum_{k=1}^{k} \sum_{i=1}^{n_{k}}\left(\mathrm{x}_{\mathrm{ik}}-\bar{x}\right)^{2}$ & $\mathrm{~N}-1$ & & \\
\hline
\end{tabular}

Tabel 3 Hasil perhitungan s pada ANOVA

\begin{tabular}{|c|c|c|c|c|c|}
\hline \multirow{2}{*}{ Sumber Variasi } & \multicolumn{5}{|c|}{ Ringkasan ANOVA } \\
\cline { 2 - 5 } & Sum Square & Df & Mean square & F hitung & F tabel \\
\hline $\begin{array}{c}\text { Antar Kelompok } \\
\text { (between) }\end{array}$ & 184,32 & 1 & 184,32 & 71,53 & \multirow{2}{*}{4,048} \\
\hline $\begin{array}{c}\text { Di dalam } \\
\text { Kelompok(Within) }\end{array}$ & 123,68 & 48 & 2,58 & & \\
\hline Total & 308,00 & 49 & 186,90 & & \\
\hline
\end{tabular}


4. Membuat keputusan apakah $\mathrm{H} 0$ diterima atau ditolak

Dari hasil perhitungan yang sudah dilakukan diketahui bahwa nilai $\mathrm{F}$ hitung > nilai $\mathrm{F}$ tabel, maka hipotesa $\mathrm{H} 0$ ditolak yang berarti bahwa ada perbedaan hasil pre test dan post test. Hal ini dapat disimpulkan bahwa kegiatan pelatihan pengenalan teknologi pengecatan di SMK palapa berjalan efektif dan dapat meningkatkan kompetensi siswa SMK tentang teknologi proses pengecatan.

\section{KESIMPULAN}

Dari pelaksanaan pengabdian masyarakat yang telah dilakukan tentang pelatihan pengetahuan teknologi proses pengecatan, para siswa SMK sangat semangat mengikuti pelatihan ini. Selain itu hasil dari pre test dan post test yang telah dilakukan mengalami peningkatan. Hal ini dapat dilihat dari perhitungan analisis varian dari kegiatan pre test dan post test. Dari hasil perhitungan menggunakan metode ANOVA diperoleh bahwa terdapat perbedaan dari kegiatan pelatihan yang telah dilakukan, hal ini berarti bahwa adanya peningkatan pengetahuan siswa SMK tentang teknologi proses pengecatan. Untuk dapat meningkatkan kualitas pengabdian selanjutnya diperlukan kritik dan saran yang bersifat membangun dari segi isi materi pelatihan serta durasi pelaksanaan pelatihan agar dapat dilakukan dalam jangka waktu tertentu. Hal ini di lakukan agar lulusan SMK dapat siap terjun ke dunia industry

\section{UCAPAN TERIMAKASIH}

Penulis mengucapkan terima kasih kepada Lembaga Penelitian dan Pengabdian Kepada Masyarakat Universitas Dian Nuswantoro yang telah memberi dukungan financial terhadap kegiatan pengabdian masyarakat ini.

\section{DAFTAR PUSTAKA}

[1] Artikel Kementrian Perindustrian, "Kementrian Perindustrian Republik indonesia," 2012.

[2] N. Islahudin, "TEKNOLOGI PROSES PENGECATAN MENGGUNAKAN SISTEM ATOMISASI PADA PRODUK BERBAHAN PLASTIK DI INDUSTRI PERAKITAN SEPEDAMOTOR,” SINTEK J. MESIN

Teknol. Univ. Muhammadiyah Jakarta, vol. 13, no. 01, pp. 15-25, 2019.

[3] R. Talbert, Paint Technology Handbook. 2010.

[4] N. Dhafr, M. Ahmad, B. Burgess, and S. Canagassababady, "Improvement of quality performance in manufacturing organizations by minimization of production defects," Robot. Comput. Integr. Manuf., 2006.

[5] PT Astra Honda Motor, "Manufacturing Process Painting Plastic," Qual. Dep., 2000.

[6] K. Witz, D. E. Hinkle, W. Wiersma, and S. G. Jurs, “Applied Statistics for the Behavioral Sciences,” J. Educ. Stat., 1990. 